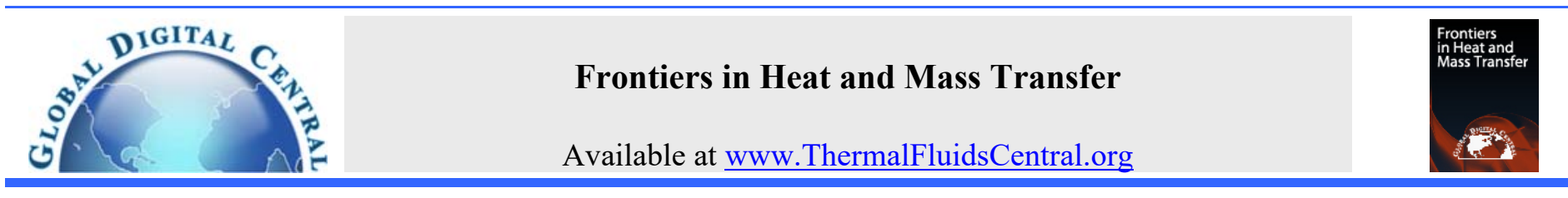

\title{
HEAT TRANSFER AND CU-WATER NANOFLUID FLOW IN A VENTILATED CAVITY HAVING CENTRAL COOLING CYLINDER AND HEATED FROM THE BELOW CONSIDERING THREE DIFFERENT OUTLET PORT LOCATIONS
}

\author{
Zoubair Boulahia*, Abderrahim Wakif, Rachid Sehaqui \\ Hassan II University, Faculty of Sciences Aïn Chock, Laboratory of Mechanics, BP 5366 Maarif, 20100 Casablanca, Morocco
}

\begin{abstract}
A numerical study has been performed to investigate mixed convection flow in a vented square cavity with circular cooling obstacle. The governing equations such as two dimensional Navier-Stokes, continuity, and energy balance equations have been solved using a finite volume discretization method with SIMPLE algorithm. The effect of the Richardson number, outlet port location and volume fraction of nanoparticles were studied. The outlet port is varied from top to bottom in order to find the maximum heat transfer rate. The results indicated that by increasing the volume fraction of nanoparticles and reducing Richardson number, the heat transfer rate is enhanced. Moreover, it is found that the best configuration of the system for better heat transfer is obtained when placing the outlet port on the bottom location of the vented cavity.
\end{abstract}

Keywords: Outlet port location; ventilated square cavity; mixed convection; circular cooling cylinder; nanofluid.

\section{INTRODUCTION}

The knowledge of mixed convection flow in a ventilated cavity is of great interest of the phenomenon in many industrial applications and in the engineering devices such as, cooling of electronic circuit boards, ventilation of rooms with radiators, pollution removal, thermal design of buildings, solar systems, cooling of containers, and heat exchangers. A literature survey shows that a great number of studies on natural and mixed convection of nanofluid in enclosures have been used obstacles with different forms and various thermal conditions. Earlier, natural convection inside the rectangular cavities without and with obstacles were reported by researchers (Guiet et al., (2012); Kolsi et al., (2016); Boulahia et al., (2016); Boulahia and Sehaqui, (2015); Boulahia et al., (2017); Boulahia et al., (2017)a; Boulahia et al., (2017)b; Boulahia et al., (2017)c; Wakif et al., (2017)a; Wakif et al., (2017)b; Wakif et al., (2018)a; Wakif et al., (2018)b; Wakif et al., (2018)c). El Abdallaoui et al., (2015) analyzed numerically the free convection of nanofluid or pure fluid inside a square cavity with decentered and centered triangular heater (El Abdallaoui et al., (2014)) using the lattice Boltzmann method. Their investigations showed that at high Rayleigh, there is an important effect on heat transfer when the triangular block is placed vertically, but at weak values of Rayleigh the heat transfer is more affected for the decentered position of the block. Kalidasan and Kanna, (2017) was concentrated on the effect of natural convection inside the open square enclosure containing a central adiabatic square obstacle. They reported that the heat transfer on the right and left wall changes with increasing the percentage of nanoparticles concentration. AlAmiri et al., (2009) obtained numerical solutions of natural heat transfer convection in square enclosure with a rectangular block placed on the bottom wall. Their investigations showed that increasing the height and width of the rectangular hot block enhances the mean Nusselt number. The same study was performed by Varol et al., (2007) and Guiet et al., (2012) for a triangular cavity.

Many studies have been performed on mixed convection of nanofluides in squares cavities (Islam et al., (2012); Khanafer and Aithal, (2013); Boulahia et al., (2016)a; Boulahia et al., (2016)b; Zoubair Boulahia et al., (2016)c). Mehrizi et al., (2012) introduced the effect of volume fraction of nanoparticles on mixed convection in a square enclosure having a central hot obstacle with inlet and outlet ports. They concluded that by increasing the solid volume fraction the heat transfer rate is enhanced at different Richardson numbers and outlet port positions. The heat transfer by mixed convection inside a vented cavity with an internal heated cylinder was studied numerically by Mamun et al., (2010). They founed that the size of the cylinder and the solid-fluid thermal conductivity has significant effect on thermal field. Bahlaoui et al., (2009) used a horizontal ventilated cavity with radiative heated bottom wall having an adiabatic thin partition. They reported that the convective Nusselt number decreases as the radiation effect increases. Kalteh et al., (2014) presented laminar mixed convection of nanofluid in a lid-driven square enclosure with a triangular heated block. They showed that increasing the nanoparticles diameter, the volume fraction and Reynolds leads to an increase in mean Nusselt number. Najam et al., (2004) investigated numerically laminar mixed convection in a " $\mathrm{T}$ ", form cavity with heated obstacles submitted to a vertical jet of fresh air from below. Shahi et al., (2010) numerically studied the mixed convection of copper-water nanofluid inside a ventilated cavity. It was found that the average Nusselt number enhances when the volume faction of nanoparticles increased. Oztop et al., (2009) used a lid driven cavity containing adiabatic, isothermal or conductive circular block. They showed that the position and the size of the inner circular body has an important effect on the heat transfer rate.

\footnotetext{
* Corresponding author. Email: boulahia.zoubair@gmail.com
} 
Rahman et al., (2012) considered an open enclosure with heated circular cylinder. They concluded that by increasing Reynolds number, the Nusselt number increases.

The main objective of the present study is to examine a mixed convection heat transfer inside a vented cavity contains a central cold cylinder and with hot temperature at the bottom wall cavity. The first case under investigation is characterized the numerical models used in our study. The computational procedure elaborated in this study is validated against the numerical results of other researches. The effects of three different outlet port locations on the right wall of cavity are chosen for investigation. Wide range of parameters such as Richardson number $(0.1 \leqslant \mathrm{Ri} \leqslant 100)$, and volume fraction of nanoparticles $(0 \leqslant \varphi \leqslant 0.05)$ have been used. The new models of the thermal conductivity and effective viscosity investigated by Corcione, (2011) are used to estimate themophysical proprieties of the nanofluid. Our numerical results are presented in the form of plots of isotherms, streamlines and mean Nusselt numbers to show the influence of nanofluid and design parameters.

\section{PROBLEM STATEMENT}

The problem configurations, coordinate system boundary conditions of the considered ventilated cavity are presented in in Fig. 1. It consists of a ventilated cavity contains a central cold cylinder with diameter $(D=0.2)$ and uniformly heated with a constant temperature, $T_{h}$, from its bottom wall while the other parts of the cavity are all thermally insulated. Three cases are considered, i.e., case A where the outlet port is located at the top position of the right wall of the cavity, case B where the outlet port is located at the medium position, and case $\mathrm{C}$ where the outlet port is located at the bottom position. The physical system is subjected to an external flow of nanofluid which passes through the vented cavity by injection. The nanofluid enters into the vented cavity from the left opening vertical wall which maintained at cold temperature, $T_{c}$, and leaves from the right opening vertical one. The length of these openings have a constant value, $h=0.1 H$. It is assumed that the nanofluid is Newtonian, incompressible and laminar (i.e, $R a \leq 10^{6}$ ) and the base fluid and the nanoparticles are in a thermal equilibrium state. The thermophysical properties of the nanofluid used in this study are evaluated at the average fluid temperature $\left(T_{c}+T_{h}\right) / 2$ as listed in Table 1 .

\section{Case A}

\section{Case B}

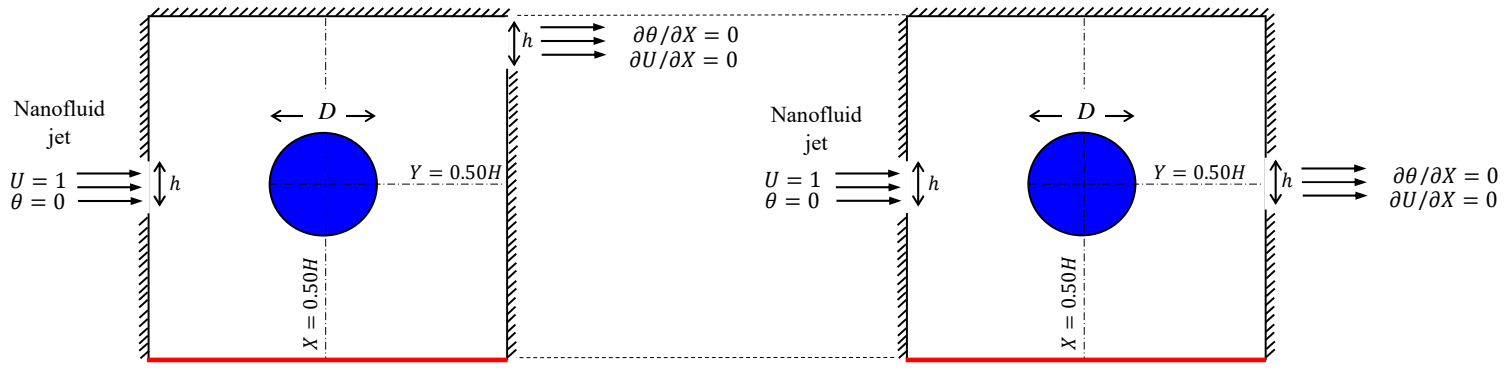

Case C
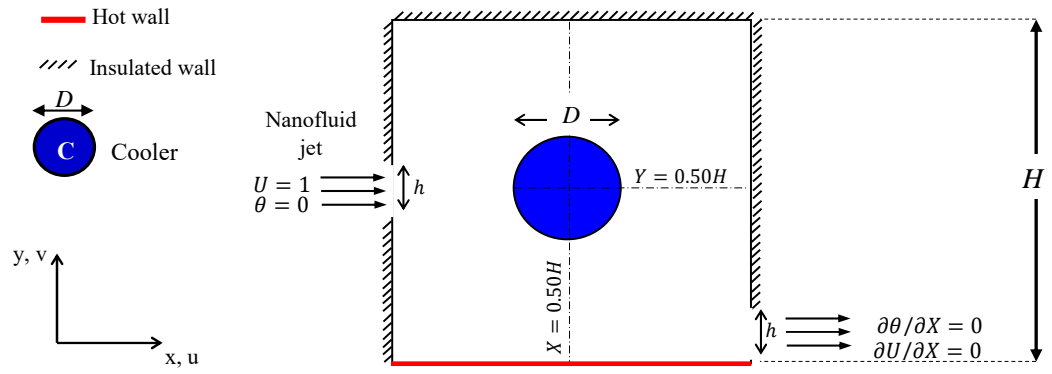

Fig. 1 Schematic of the ventilated cavity with different outlet port locations having a circular cooling cylinder and boundary conditions.

Table 1 Thermo-physical properties of water and nanoparticles at $\mathrm{T}=$ $300 \mathrm{~K}$ (Incropera and De Witt, (2002))

\begin{tabular}{lll}
\hline & Copper $(\mathrm{Cu})$ & Water $\left(\mathrm{H}_{2} \mathrm{O}\right)$ \\
\hline$C_{p}(\mathrm{~J} / \mathrm{Kg} \mathrm{K})$ & 385 & 4179 \\
$\rho\left(\mathrm{Kg} / \mathrm{m}^{3}\right)$ & 8933 & 997.1 \\
$k(\mathrm{~W} / \mathrm{mK})$ & 401 & 0.6 \\
$\beta\left(\mathrm{K}^{-1}\right)$ & $1.6710^{-5}$ & $27.610^{-5}$ \\
$\mu\left(\mathrm{kg} \mathrm{m}^{-1} \mathrm{~s}^{-1}\right)$ & - & $0.85510^{-3}$ \\
\hline
\end{tabular}

\section{MATHEMATICAL FORMULATION}

The governing equations including the two-dimensional transient equations of the continuity, momentum and energy for an incompressible flow are expressed in the following format:

$$
\begin{aligned}
& \frac{\partial u}{\partial x}+\frac{\partial v}{\partial y}=0 \\
& \frac{\partial u}{\partial t}+u \frac{\partial u}{\partial x}+v \frac{\partial u}{\partial y}=-\frac{1}{\rho_{n f}} \frac{\partial p}{\partial x}+\frac{\mu_{n f}}{\rho_{n f}}\left(\frac{\partial^{2} u}{\partial x^{2}}+\frac{\partial^{2} u}{\partial y^{2}}\right) \\
& \frac{\partial v}{\partial t}+u \frac{\partial v}{\partial x}+v \frac{\partial v}{\partial y}=-\frac{1}{\rho_{n f}} \frac{\partial p}{\partial y}+\frac{\mu_{n f}}{\rho_{n f}}\left(\frac{\partial^{2} v}{\partial x^{2}}+\frac{\partial^{2} v}{\partial y^{2}}\right) \\
& +\frac{(\rho \beta)_{n f}}{\rho_{n f}}\left(T-T_{c}\right) g \\
& \frac{\partial T}{\partial t}+u \frac{\partial T}{\partial x}+v \frac{\partial T}{\partial y}=\alpha_{n f}\left(\frac{\partial^{2} T}{\partial x^{2}}+\frac{\partial^{2} T}{\partial y^{2}}\right)
\end{aligned}
$$

where the nanofluid effective density, heat capacity, thermal expansion coefficient and thermal diffusivity are calculated from the following equations (Haddad et al., (2012); Corcione, (2010)):

$$
\rho_{n f}=(1-\varphi) \rho_{f}+\varphi \rho_{s}
$$




$$
\begin{aligned}
& \left(\rho C_{p}\right)_{n f}=(1-\varphi)\left(\rho C_{p}\right)_{f}+\varphi\left(\rho C_{p}\right)_{s} \\
& (\rho \beta)_{n f}=(1-\varphi)(\rho \beta)_{f}+\varphi(\rho \beta)_{s} \\
& \alpha_{n f}=k_{n f} /\left(\rho C_{p}\right)_{n f}
\end{aligned}
$$

Corcione models (Corcione, (2010); Corcione, (2011)) for the dynamic viscosity and the thermal conductivity of the nanofluid are given by:

$$
\begin{aligned}
& \mu_{n f}=\mu_{f} /\left(1-34.87\left(d_{p} / d_{f}\right)^{-0.3} \varphi^{1.03}\right) \\
& \frac{k_{n f}}{k_{f}}=1+4.4 \operatorname{Re}_{B}^{0.4} \operatorname{Pr}^{0.66}\left(\frac{T}{T_{f r}}\right)^{10}\left(\frac{k_{p}}{k_{f}}\right)^{0.03} \varphi^{0.66} \\
& \operatorname{Re}_{B}=\frac{\rho_{f} u_{B} d_{p}}{\mu_{f}} \\
& u_{B}=\frac{2 k_{b} T}{\pi \mu_{f} d_{p}^{2}}
\end{aligned}
$$

The boundary conditions for mixed convection written as:

$$
\begin{array}{lll}
u=0, & v=0, \quad T=T_{h} & \text { on bottom wall } \\
u=0 & v=0, \quad \partial T / \partial y=0 & \text { on upper wall } \\
u=0, \quad v=0, \quad \partial T / \partial x=0 & \text { on right wall } \\
u=0, \quad v=0, \partial T / \partial x=0 & \text { on left wall } \\
u=U_{0}, \quad v=0, T=T_{c} & \text { on inlet port } \\
\partial u / \partial x=0, \quad v=0, \partial T / \partial x=0 & \text { on outlet port } \\
u=0, \quad v=0, T=T_{c} & \text { on block }
\end{array}
$$

The following dimensionless variables for mixed convection are defined based on properties of pure fluid:

$$
\begin{gathered}
\tau=\frac{t}{\frac{H}{U_{\text {ref }}}}, \quad X=\frac{x}{H}, \quad Y=\frac{y}{H}, \quad U=\frac{u}{U_{\text {ref }}}, \\
V=\frac{v}{U_{\text {ref }}}, \quad P=\frac{p}{\rho_{\text {nf }} U_{\text {ref }}^{2}}, \quad \theta=\frac{T-T_{c}}{T_{h}-T_{c}},
\end{gathered}
$$

where $U_{\text {ref }}$ is considered to be $U_{0}$ for mixed convection. Dimensionless numbers for the system are defined as:

$$
\begin{aligned}
& R e=\frac{u_{r e f} H}{v_{f}}, \quad R i=\frac{G r}{R e^{2}}, \quad G r=\frac{g \beta_{f}\left(T_{h}-T_{c}\right) H^{3}}{v_{f}^{2}} \\
& R a=G r \cdot P r=\frac{g \beta_{f}\left(T_{h}-T_{c}\right) H^{3}}{\alpha_{f} v_{f}}, \quad \operatorname{Pr}=\frac{v_{f}}{\alpha_{f}},
\end{aligned}
$$

The governing equations (1)-(4) are written in the following dimensionless form:

$$
\begin{aligned}
& \frac{\partial U}{\partial X}+\frac{\partial V}{\partial Y}=0 \\
& \frac{\partial U}{\partial \tau}+U \frac{\partial U}{\partial X}+V \frac{\partial U}{\partial Y}=-\frac{\partial P}{\partial X}+\frac{1}{R e} \frac{\rho_{f}}{\rho_{n f}} \frac{\mu_{n f}}{\mu_{f}}\left(\frac{\partial^{2} U}{\partial X^{2}}+\frac{\partial^{2} U}{\partial Y^{2}}\right) \\
& \frac{\partial V}{\partial \tau}+U \frac{\partial V}{\partial X}+V \frac{\partial V}{\partial Y}=-\frac{\partial P}{\partial Y}+\frac{1}{R e} \frac{\rho_{f}}{\rho_{n f}} \frac{\mu_{n f}}{\mu_{f}}\left(\frac{\partial^{2} V}{\partial X^{2}}+\frac{\partial^{2} V}{\partial Y^{2}}\right) \\
& +R i \frac{(\rho \beta)_{n f}}{\rho_{n f} \beta_{f}} \theta \\
& \frac{\partial \theta}{\partial \tau}+U \frac{\partial \theta}{\partial X}+V \frac{\partial \theta}{\partial Y}=\frac{1}{R e \cdot P r} \frac{\alpha_{n f}}{\alpha_{f}}\left(\frac{\partial^{2} \theta}{\partial X^{2}}+\frac{\partial^{2} \theta}{\partial Y^{2}}\right)
\end{aligned}
$$

Dimensionless form of the boundary conditions can be written as:

$$
\begin{array}{lll}
U=0, & V=0, \quad \theta=1 & \text { on bottom wall } \\
U=0, & V=0, \quad \partial \theta / \partial Y=0 & \text { on upper wall } \\
U=0, \quad V=0, \quad \partial \theta / \partial X=0 & \text { on right wall } \\
U=0, \quad V=0, \quad \partial \theta / \partial X=0 & \text { on left wall } \\
U=1, \quad V=0, \quad \theta=0 & \text { on inlet port } \\
\partial U / \partial X=0, \quad V=0, \quad \partial \theta / \partial X=0 & \text { on outlet port } \\
U=0, \quad V=0, \quad \theta=0 & \text { on block }
\end{array}
$$

The dimensionless stream function can be written as:

$\psi=-\int_{Y_{o}}^{Y} U \partial Y+\psi\left(X, Y_{0}\right)$

where $\psi_{\max }=\max (\psi)$

The total mean Nusselt number of all cavity's wall is defined as:

$$
\overline{N u}_{t o t}=\frac{1}{H} \int_{0}^{H} \frac{k_{n f}(\varphi)}{k}\left\{\left|\frac{\partial \theta}{\partial Y}\right|_{\text {bottom }}\right\} d X
$$

\section{NUMERICAL DETAILS}

The discretization procedure of the governing equations (Eqs. (17)-(20)) and boundary conditions described by Eq. (21) is based on a finite volume formulation, given by Patankar, (1980) on a staggered grid. SIMPLE (Semi-Implicit Method for Pressure Linked Equations) is used to solve the coupled pressure-velocity equation while Hybrid Differencing Scheme (HDS) of Spalding, (1972) is used for the convective terms.

The key step of the finite volume method is the integration of the dimensionless governing equations (17)-(20) over a two-dimensional control volume $\mathrm{CV}$. The integration of the transport equation may be written in a generic form for the variable $\phi$ as :

$$
\int_{C V} \frac{\partial \phi}{\partial t} d V+\int_{C V}\left(U \frac{\partial \phi}{\partial X}+V \frac{\partial \phi}{\partial Y}\right) d V=\int_{C V} \Gamma\left(\frac{\partial^{2} \phi}{\partial X^{2}}+\frac{\partial^{2} \phi}{\partial Y^{2}}\right) d V+\int_{C V} S d V
$$

where $S$ is the source term and $d V=d X . d Y$

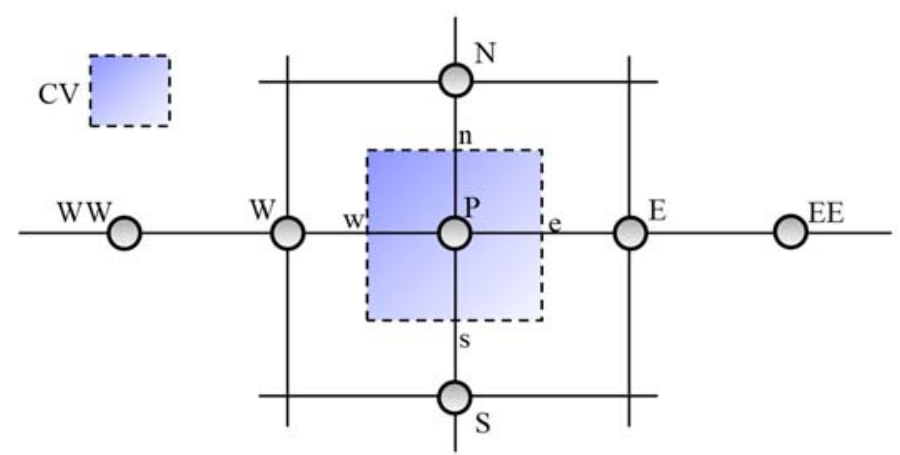

Fig. 2 Typical control volume CV

After integration, the algebraic finite volume equations for the momentum and energy equations are written into the following form:

$$
a_{P} \phi_{P}=a_{W} \phi_{W}+a_{E} \phi_{E}+a_{S} \phi_{S}+a_{N} \phi_{N}+S_{\phi}
$$

where P, W, E, N, S denote cell location, west face of the control volume, east face of the control volume, north face of the control volume and south face of the control volume CV respectively (see Fig. 2).

The Line by line application of TDMA (Tri-Diagonal Matrix Algorithm) method (Spalding, (1972)) is applied on the system of equations until sum of the residuals became less than $10^{6}$. The developed algorithm was implemented in FORTRAN program. 


\subsection{Grid independence study}

In order to determine a proper grid for the numerical simulation, a square ventilated cavity filled with $\mathrm{Cu}-$ water nanofluid $(\varphi=5 \%)$ having a circular cooling cylinder with diameter $(D=0.2)$ is analyzed in two extreme Richardson numbers $(\mathrm{Ri}=0.1$ and 100). The mean Nusselt number obtained using different grid numbers for particular cases is presented in Table 2. As can be observed from the table, a non-uniform $103 \times 103$ grid is sufficiently fine for the numerical calculation.

Table 2 Effect of the grid size on $\overline{N u}$ for the ventilated cavity filled with the $\mathrm{Cu}-$ water nanofluid $(\varphi=0.05)$ with a circular cooling cylinder with diameter $D=d / H=0.2$ for case C (see Fig. 1)

\begin{tabular}{lllll}
\hline$R i$ & $63 \times 63$ & $83 \times 83$ & $103 \times 103$ & $123 \times 123$ \\
\hline 0.1 & 22.187 & 22.667 & 22.712 & 22.717 \\
100 & 5.722 & 6.150 & 6,238 & 6.249 \\
\hline
\end{tabular}

\subsection{Validations}

In order to validate the present code against various numerical results available in the literature some different heat convection problems are chosen. The first case is the benchmark problem of natural convection in a square cavity which considered by De Vahl Davis, (1983) filled with Air $(\operatorname{Pr}=0.71)$. Table 3 demonstrates an excellent comparison of the average Nusselt number between the present results and the numerical results found in the literature (Barakos et al., (1994); Dixit and Babu, (2006)). The numerical results of Iwatsu et al., (1993) and Oztop et al., (2009) for a top heated moving lid and bottom cooled square cavity filled

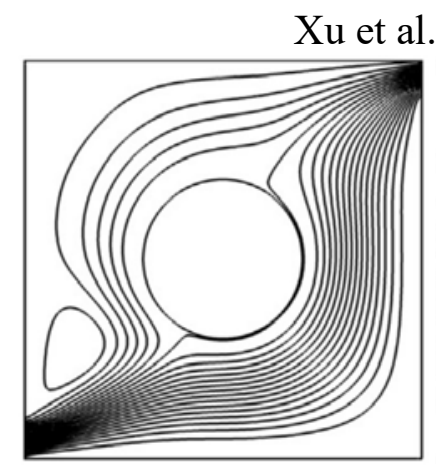

Streamlines

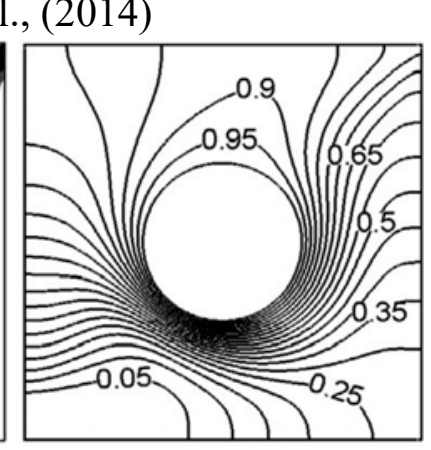

Isotherms
Present study

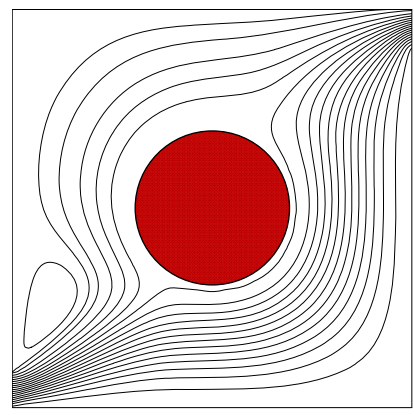

Streamlines

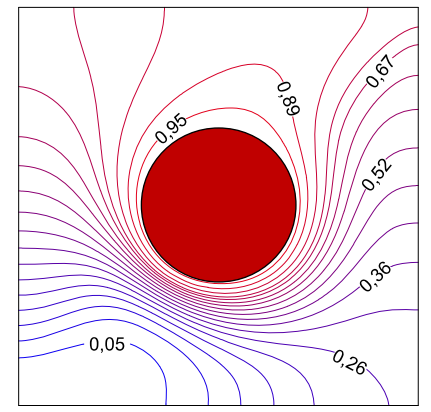

Isotherms

with air $(\operatorname{Pr}=0.71)$. A $100 \times 100$ mesh was used and the computations were done for three different Richardson numbers. Table 4 demonstrates an excellent comparison of the average Nusselt number between the present results and the numerical results found in the literature (Iwatsu et al., (1993); Oztop et al., (2009)) with a maximum discrepancy of about $1.6 \%$.

Finally, we chose two other different convection problems (natural and mixed convection) to compare the flow structure. Fig. 3 illustrates the comparison of the isotherms and streamlines with that of mixed convection flow in vented cavity contains a circular heater reported by $\mathrm{Xu}$ et al., (2014) at $(\mathrm{Pr}=0.7, \mathrm{Ri}=1.0, \mathrm{Br}=1.0, \mathrm{Le}=0.1)$ and with a natural convection heat transfer and flow structures in a square enclosure with circular heater reported by Park et al., (2013) $\left(\mathrm{Ra}=10^{6}, \mathrm{Pr}=0.7\right)$.

Table 3 Comparison of $\overline{N u}$ between the present results and those reported in the literature for a DHC at different Rayleigh numbers.

\begin{tabular}{lllll}
\hline$R a$ & $10^{3}$ & $10^{4}$ & $10^{5}$ & $10^{6}$ \\
\hline $\begin{array}{l}\text { De Vahl Davis, (1983) } \\
\text { Relative Error (\%) }\end{array}$ & 1.118 & 2.243 & 4.519 & 8.799 \\
& 0.17 & 0.13 & 0.75 & 0.54 \\
Barakos et al., (1994) & 1.114 & 2.245 & 4.510 & $\begin{array}{l}8.806 \\
\text { Relative Error (\%) }\end{array}$ \\
& 0.17 & 0.22 & 0.55 & 0.62 \\
Dixit and Babu, (2006) & 1.118 & 2.256 & 4.519 & 8.817 \\
Relative Error (\%) & 0.17 & 0.71 & 0.75 & 0.75 \\
& & & & \\
Present study & $\mathbf{1 . 1 1 6}$ & $\mathbf{2 . 2 4 0}$ & $\mathbf{4 . 4 8 5}$ & $\mathbf{8 . 7 5 1}$ \\
Grid size & $83^{2}$ & $83^{2}$ & $83^{2}$ & $103^{2}$ \\
\hline
\end{tabular}

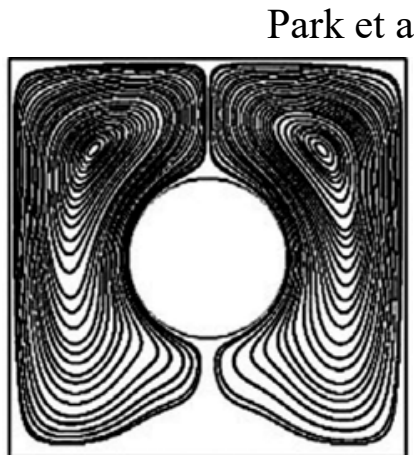

Streamlines

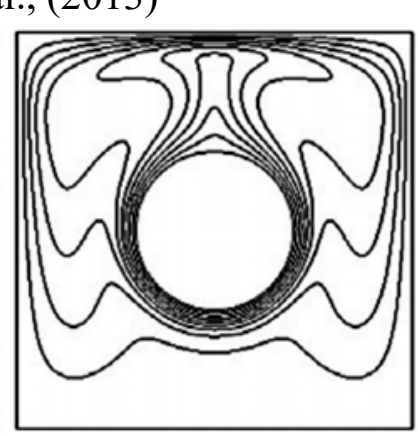

Isotherms

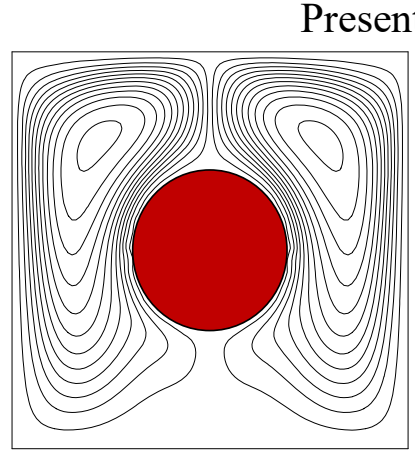

Streamlines

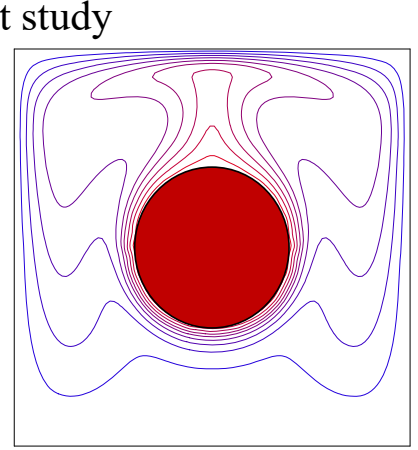

Isotherms

Fig. 3. Comparison of the isotherms and streamlines with that of Parck et al., (2013) $(\mathrm{Ra}=106, \mathrm{Pr}=0.7)$ and $\mathrm{Xu}$ et al., (2014) $(\mathrm{Pr}=0.7, \mathrm{Ri}=1.0$, $\mathrm{Br}=1.0, \mathrm{Le}=0.1)$. 
Table 4 Comparison of $\overline{N u}$ at the hot lid between the present results and those reported in the literature

\begin{tabular}{llll}
\hline \multirow{2}{*}{$R i$} & \multicolumn{3}{l}{ Average Nusselt number at the hot lid } \\
\cline { 2 - 4 } & Iwatsu et al., (1993) & Oztop et al., (2009) & Present \\
\hline 1.0 & 1.34 & 1.30 & $\mathbf{1 . 3 6}$ \\
0.0625 & 3.62 & 3.63 & $\mathbf{3 . 6 8}$ \\
0.01 & 6.29 & 6.34 & $\mathbf{6 . 2 9}$ \\
\hline
\end{tabular}

\section{RESULTS AND DISCUSSION}

In this section, the mixed convection heat transfer inside a ventilated cavity contains a central cold cylinder with hot temperature at the bottom wall is under study. The effect of three different outlet port locations on the right wall of the cavity (Case A, B and C), and volume fraction ( $0 \leq$ $\varphi \leq 0.05$ ) on heat transfer rate are discussed. The size of the circular cooler, $d$, is fixed at $0.2 H$ while the Grashof number, $G r$, is kept constant at $10^{4}$.
$R i$

\section{Case A}

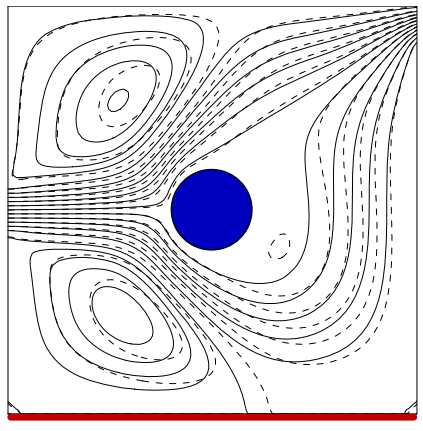

1
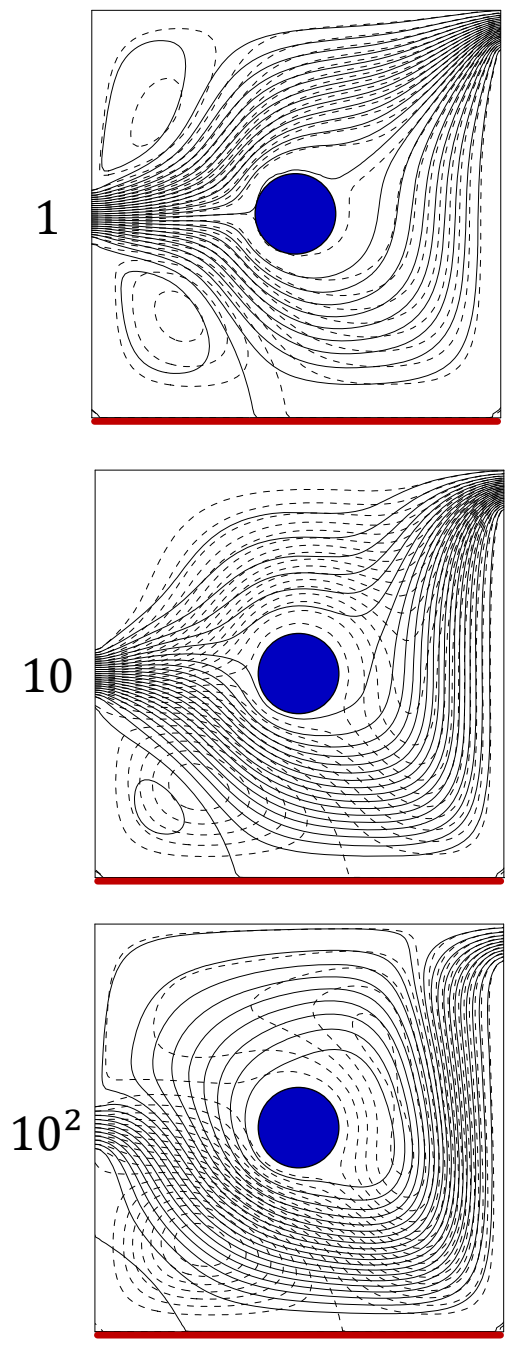

Case B
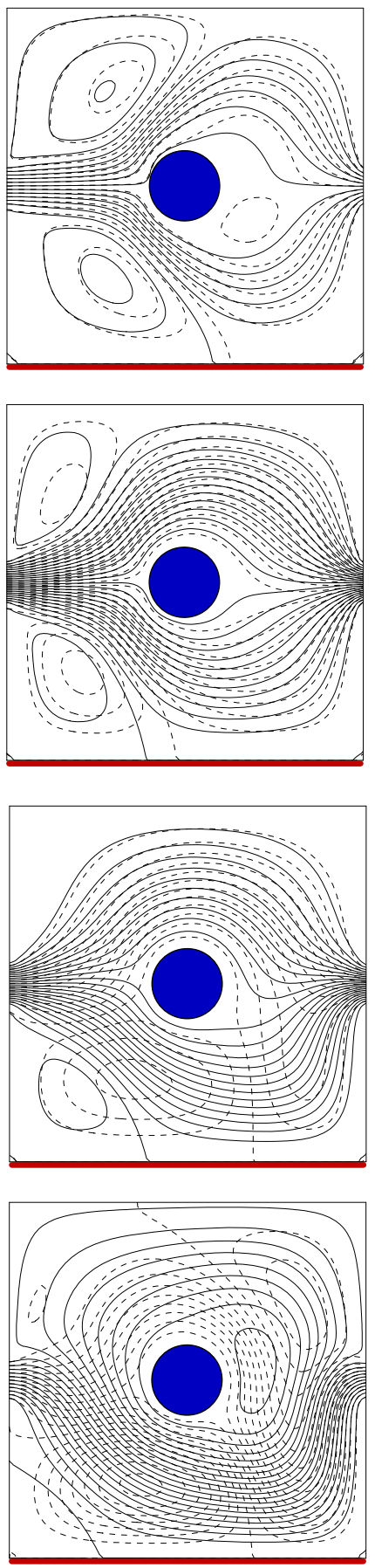

Case C
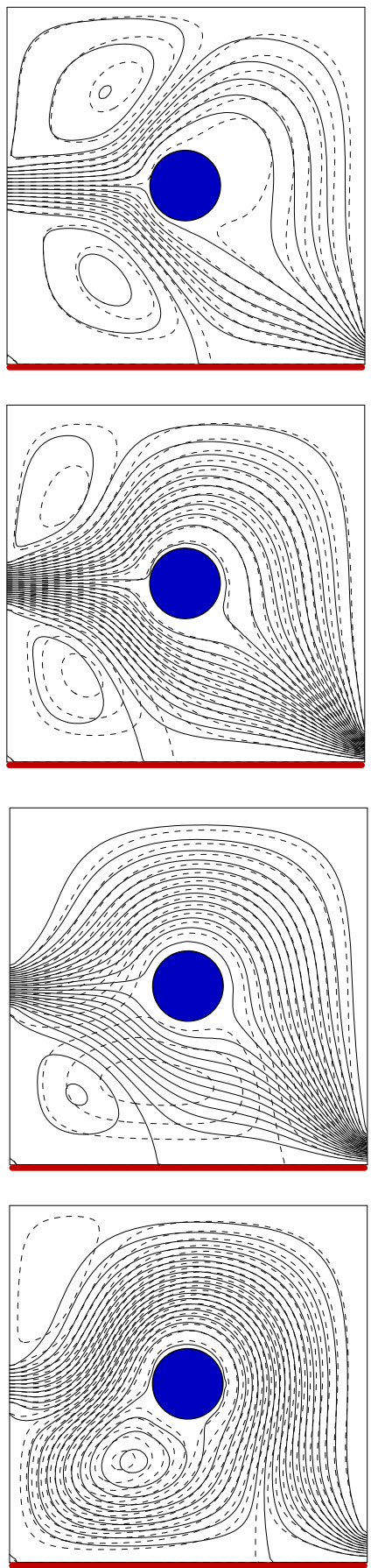

Fig. 4. Streamlines inside the ventilated cavity contains a circular cooler $(D=d / H=0.2)$, and filled with the pure fluid (dashed line) and $\mathrm{Cu}-$ water nanofluid (solid line) with $\varphi=5 \%$ and at different $R$ is for cases A, B and C. Gr $=10^{4}$. 
Four different values of Reynolds number $(\mathrm{Re}=10,31.62,100$, and $316.22)$ are chosen to cover forced $(\mathrm{Ri}=0.1)$, mixed $(\mathrm{Ri}=1)$ and natural convection $(\mathrm{Ri}=10$ and $\mathrm{Ri}=100)$ regimes. The variation of Reynolds number $\left(\operatorname{Re}=U_{0} H / v\right)$ is made by changing the velocity $\left(U_{0}\right)$ of the incoming flow. The effects of Richardson number, Ri, ranging from 0.1 to 100 and the three different outlet port locations (Case A, B and C) on streamlines and isotherms are shown in Fig. 4 and 5. The ventilated square cavity filled with $\mathrm{Cu}$-water is analyzed for case $\mathrm{A}, \mathrm{B}$ and $\mathrm{C}$. For comparisons, the streamlines and the isotherms for pure fluid and nanofluid are shown by dashed line and solid line respectively. It can be seen from Fig. 4 and 5 that, there is some differences in streamlines and isotherms of pure fluid and nanofluid, which we can explain by the higher viscosity of nanofluid compared to that of the pure fluid which increases the diffusion of momentum in the nanofluid. Generally, the cold inlet fluid moves over the central cylinder before leaving the cavity, the arriving flow strikes to the left side of the cold cylinder, where the flow is directed from the inlet port toward top and down of the cooler and moves to the outlet port.
Ri Case A

0.1

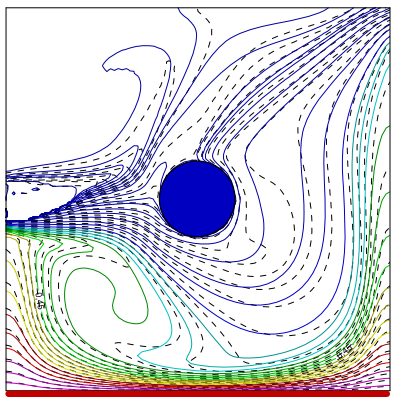

1

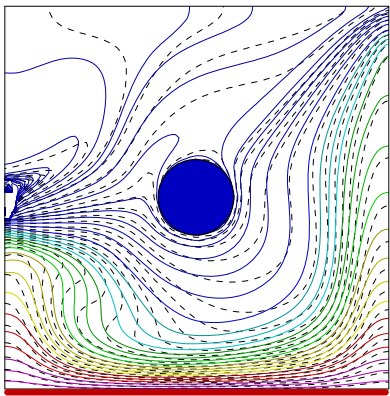

10
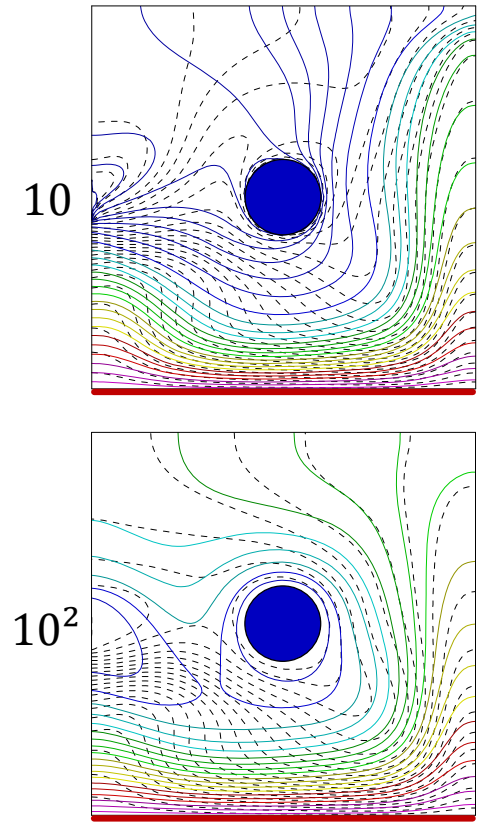

Case B
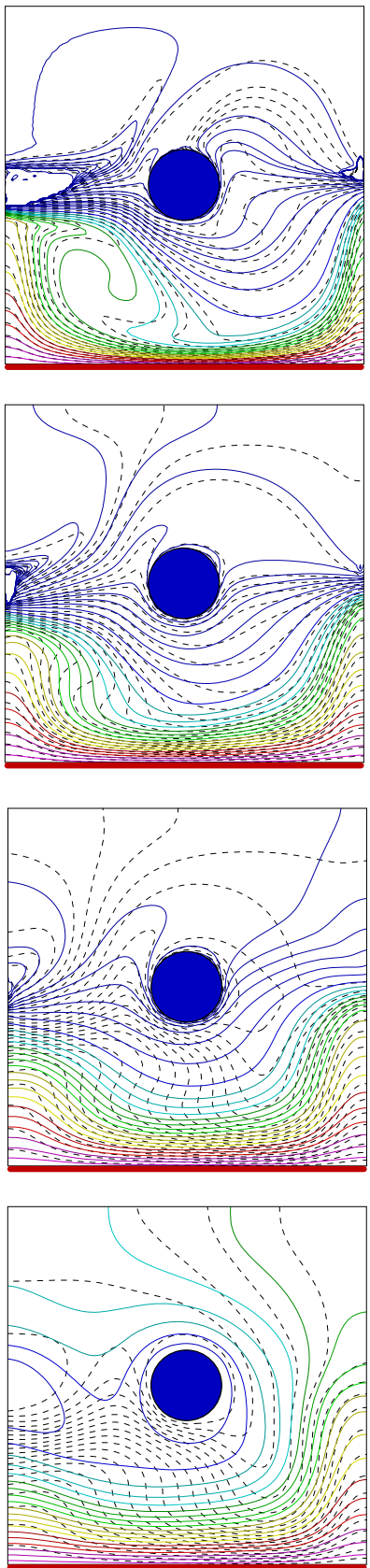

Case C
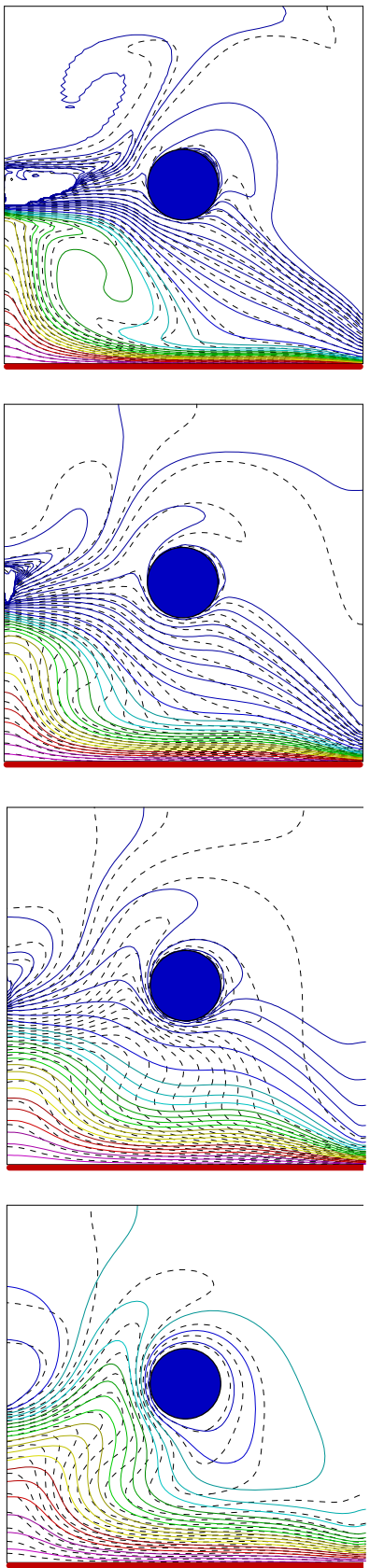

Fig. 5. Isotherms inside the ventilated cavity contains a circular cooler $(D=d / H=0.2)$, and filled with the pure fluid (dashed line) and $\mathrm{Cu}-$ water nanofluid (solid line) with $\varphi=5 \%$ and at different $R i$ for cases A, B and C. Gr $=10^{4}$.

For $R i=0.1$ where the forced convection dominates the flow characteristics, the streamlines shown in Fig. 4 demonstrate that the incoming flow mainly passes over the cold cylinder and produces two small rotating cells located on the top and bottom left of the cavity corresponding to the inlet-outlet axis line. In addition, it is clearly observed that the outer and inner rotating vortices occupy a considerable 
space. The pattern of the streamlines where the circulating vortices near the inlet port almost change with the position of the outlet port (Fig.4 : case $\mathrm{A}, \mathrm{B}$ and $\mathrm{C})$. By increasing the Richardson number $(\mathrm{Ri}>=1)$, the main flow traverses bottom of the cold cylinder which is due to decreasing of the incoming flow velocity. At $\mathrm{Ri}=1$, mixed convection heat transfer is the dominant regime. The fluid flow occupies the whole of the ventilated cavity and bifurcates near the cold cylinder. It is clearly observed that by increasing $\mathrm{Ri}$ to 1 , the circulating vortices near the inlet port become smaller in comparison with that of $\mathrm{Ri}=0.1$, due to increased inertia force. The size of the corresponding vortices is bigger for the pure fluid than the nanofluid, it can be explained by the role of forced convection which is more significant for the pure fluid. At this two values of Richardson number $(\mathrm{Ri}=0.1$ and 1$)$, the outlet port position (Fig.4: case $\mathrm{A}, \mathrm{B}$ and $\mathrm{C}$ ) has not a significant effect on the streamlines distribution near the inlet port due to the mixed and forced convection are dominant.

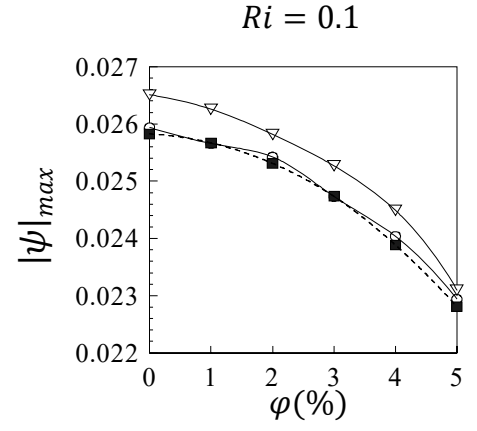

- Case A

- Case B

Case $C$

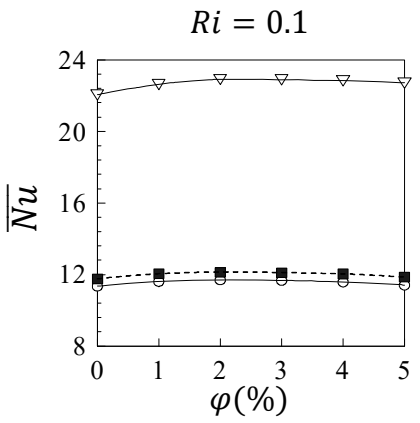

- Case A

- Case B

Case $C$

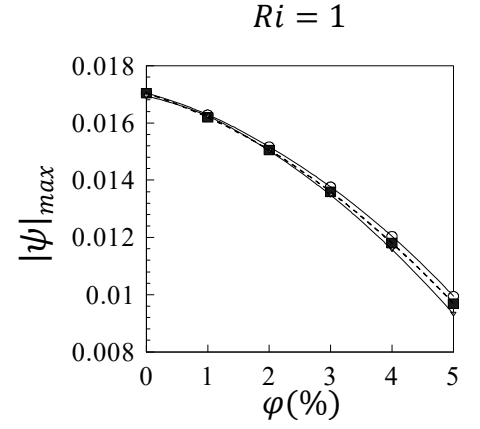

- Case A

- Case B

Case $C$

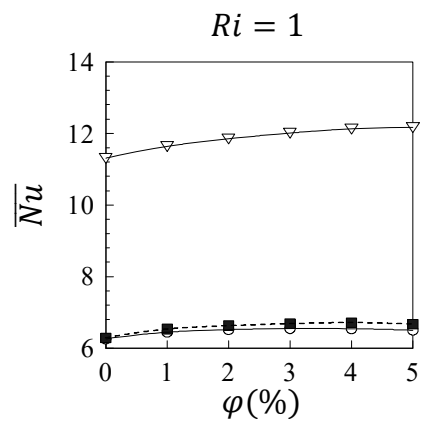

- Case A

- Case B

Case C

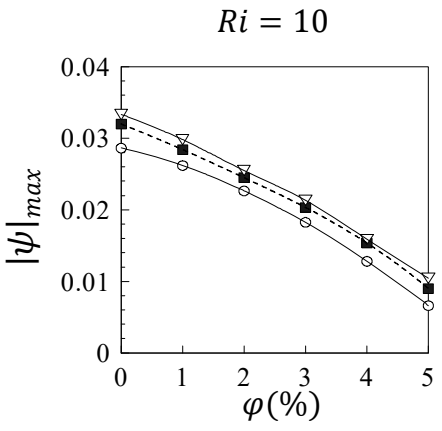

- Case A
$-\quad$ Case B
$-\quad$ Case C

(a)

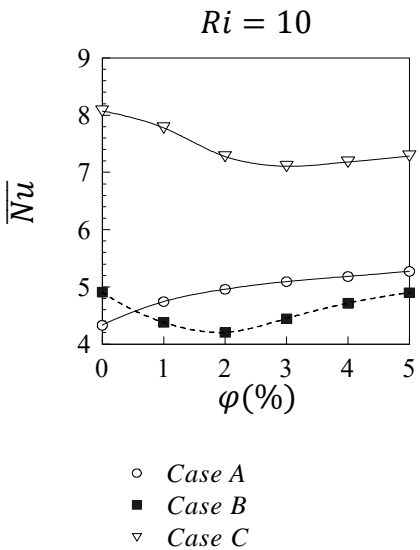

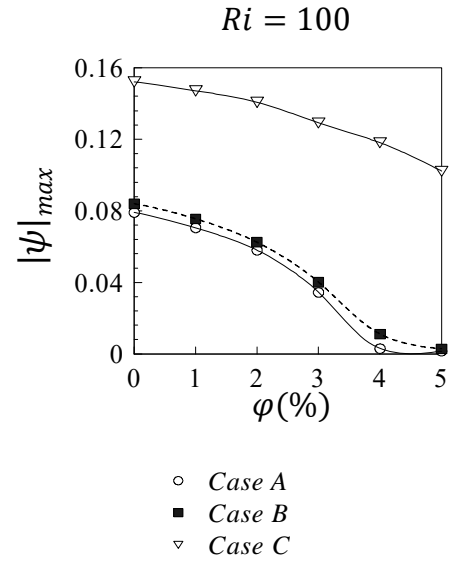

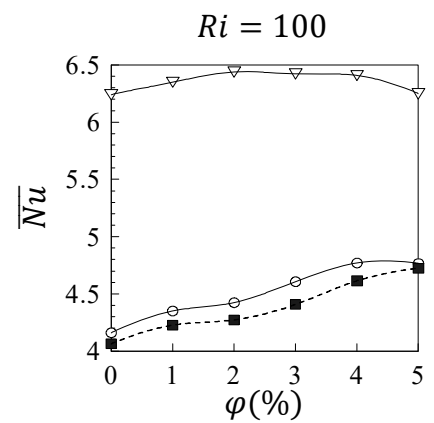

Case A

- Case B

Case C

(b)

Fig. 6. Variation of (a) $|\psi|_{\max }$ and (b) $\overline{N u}$ with respect to the volume fraction of the nanoparticles at different Richardson numbers, size and type of nanoparticles. $G r=10^{4}$.

It is predictable that with increasing the $\mathrm{Ri}$ to 10 , the circulating vortices near the inlet port almost disappear due to natural convection increases. Therefore, most flow passes through the bottom region. Fig. 4 displays at this Richardson number $(\mathrm{Ri}=10)$ that the streamlines form at the left side of the circular cold block is affected by the outlet position. It is clearly observed that the small rotating cell located on the bottom left of the cavity changes with the outlet port locations (case A, B and C).

At high Richardson number $(\mathrm{Ri}=100)$, the role of natural convection in formation of flow pattern becomes greater and consequently we can see from Fig. 4 a larger portion of the flow gets in contact with the heated bottom wall indicating a good convective heat exchange. At this Ri, the outlet port position has a considerable effect on the streamlines distribution and the form of the flow in the vented cavity. When the location of outlet port changes from top (case A) to the bottom (case C), the flow which passes at the bottom of the circular cooler increases.

The isotherms exhibited in Fig. $5(\mathrm{Ri}=0.1)$ are tightened on the heated bottom wall which indicate a good convective heat exchange. For all Richardson number, the intensity of the isotherms at the vicinity of the heated bottom wall increases by changing the outlet port from top to bottom position (case $\mathrm{A}, \mathrm{B}$, and $\mathrm{C}$ ). At $\mathrm{Ri}=0.1$, a large space of the vented cavity is at a uniform cold temperature due to the forced convection is dominant, where the heat provided by the hot wall without passing through the top space of the vented cavity. It can be seen from Fig. 5 at $\mathrm{Ri}=1$, that the isotherms are less tightened with the heated bottom wall in comparison with pervious case $(\mathrm{Ri}=0.1)$. A further increase of $\mathrm{Ri}$ up to 1 , as shown in Fig. 5, leads to decrease the cold zone of the vented cavity in favor of the thermal boundary layer which can be explained by effect of the mixed convection. The isotherms also take the shape of the circular cooler (see Fig. 5). For $\mathrm{Ri}=100$ (Fig. 5), the isotherms have more deflection on the left side of the circular cold obstacle, in this case, the role of natural convection becomes greater and consequently the cold zone of the vented cavity decrease more.

Fig. 6(a-b) shows values of $|\psi|_{\text {max }}$ and $\overline{N u}_{\text {tot }}$ in the same conditions of Fig. 4 and 5 at different outlet port locations (Case A, B and C), Richardson number and volume fraction of nanoparticles. The maximum stream function $|\psi|_{\max }$ shows in Fig. 4(a) decreases at all Ri number by 
increasing volume fraction of nanoparticles, we can explain the decrease of $|\psi|_{\text {max }}$ by Eq. (9) which indicates that the increasing volume fraction of the nanoparticles, leads to increase in the viscosity of the fluid. Fig. 6(b) shows that changing the outlet port location from top to bottom has a significant effect on the heat transfer rate. Results reveals that the mean Nusselt number increases with reduction of Richardson number. At all Richardson number, it is clear that the most preferable heat transfer is obtained, when the outlet port of the vented cavity is placed on the bottom location (see Fig. 6(b): case C). At low Richardson number $(\mathrm{Ri}=0.1$ and 1) the effect of forced and mixed convection regime is dominant, so we can observe from Fig. 6(b) that there is no significant effect between case $\mathrm{A}$ and $\mathrm{B}$. At the corresponded $\mathrm{Ri}$, the heat transfer rate changes weakly with the volume fraction of the nanoparticles and reaches its maximum value when the volume fraction is equal $2 \%$ for the most cases. By increasing Richardson number beyond 1 , we can clearly observe that case A has become the best for a good heat transfer compared to the case B due to the dominance of the natural convection regime and the effect of the circular block, which hinders the flow of the nanofluid for case B than A.

\section{CONCLUSION}

Simulation of the mixed convection heat transfer inside a ventilated cavity contains a central cold cylinder was investigated by the finite volume method. The numerical results are realized for various values of Richardson number $(0.1 \leq R i \leq 100)$ and volume fraction of nanoparticles $(0 \leq \varphi \leq 0.05)$. Three different outlet port locations on the right wall of the cavity (Case A, B and C) are studied. According to the presented results, the following conclusions are drawn:

- The circular cylinder, the outlet port location, Richardson number, and volume fraction has a significant effect on the streamlines and isotherms.

- At all Ri number, the maximum stream function $|\psi|_{\text {max }}$ decreases by increasing volume fraction of nanoparticles due to the increase in the viscosity of the nanofluid.

- At all Ri number, changing the outlet port location from top to bottom has a significant effect on the heat transfer rate.

- The best configuration of the system for batter heat transfer is obtained when placing the outlet port on the bottom location of the vented cavity (case C).

- At low Richardson number ( $\mathrm{Ri}=0.1$ and 1$)$, there is no significant effect on the heat transfer rate between case A and B, it changes weakly with the volume fraction of the nanoparticles and reaches its maximum value when the volume fraction is equal $2 \%$ for the most cases.

- By increasing Richardson number beyond 1, the case A has become the best for a good heat transfer compared to the case B due to the effect of natural convection and the circular cold cylinder.

\section{ACKNOWLEDGMENTS}

The authors wish to express their very sincerely thanks to the reviewers for their valuable and lucid comments which have improved the paper appreciably.

\section{NOMENCLATURE}

$C_{p} \quad$ specific heat, $\mathrm{Jkg}^{-1} \mathrm{~K}^{-1}$

$d_{p} \quad$ diameter of the nanoparticle, $m$

$d_{f} \quad$ diameter of the base fluid molecule, $m$

$d \quad$ diameter of circular cooler, $m$

$D$ dimensionless diameter of circular cooler

$g \quad$ gravitational acceleration, $\mathrm{m} \mathrm{s}^{-2}$

Gr Grashof number $\left(=g \beta \Delta T H^{3} / v^{2}\right)$

$H \quad$ height of the ventilated cavity, $\mathrm{m}$

$h \quad$ wide of inlet port, $\mathrm{m}$

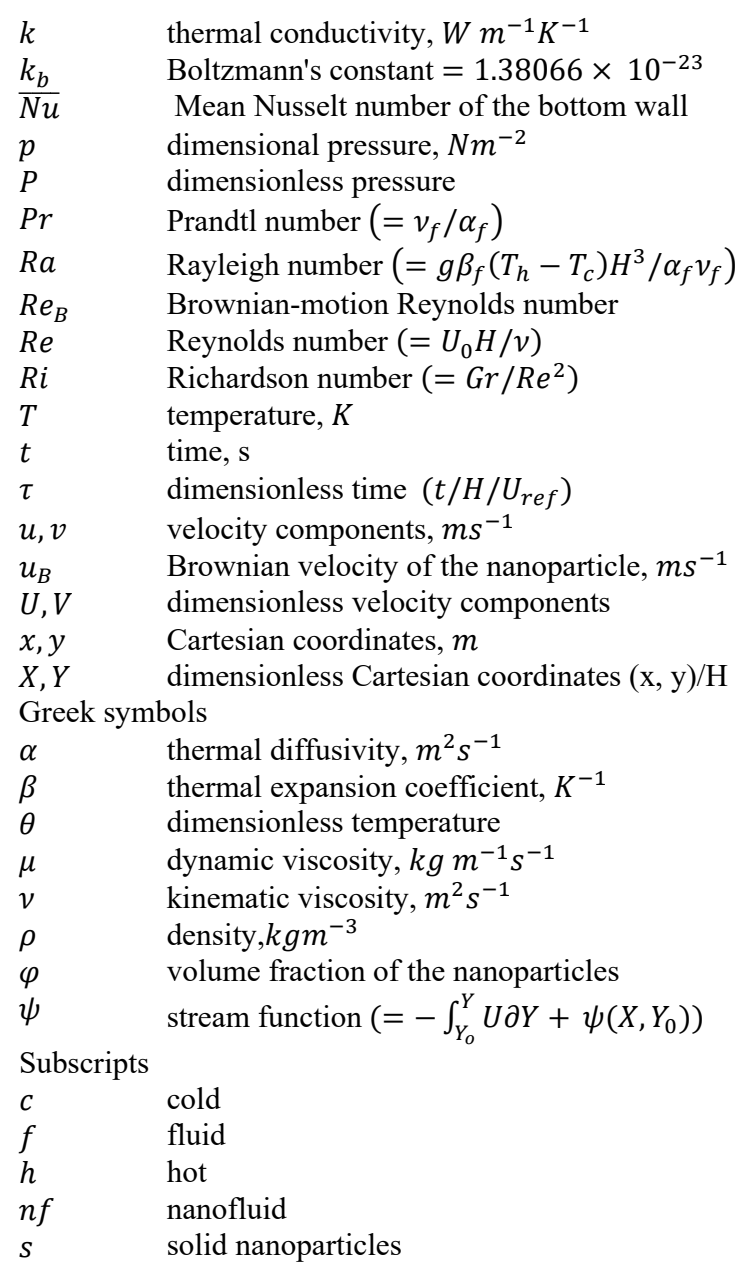

\section{REFERENCES}

AlAmiri, A., Khanafer, K., and Pop, I. 2009. "Buoyancy-induced flow and Heat Transfer in a Partially Divided Square Enclosure." International Journal of Heat and Mass Transfer, 52(15-16), 3818-3828. https://doi.org/10.1016/j.ijheatmasstransfer.2009.01.043

Bahlaoui, A., Raji, A., Hasnaoui, M., Naïmi, M., Makayssi, T., and Lamsaadi, M. 2009. "Mixed Convection Cooling Combined with Surface Radiation in a Partitioned Rectangular Cavity." Energy Conversion and Management, 50(3), 626-635.

https://doi.org/10.1016/j.enconman.2008.10.001

Barakos, G., Mitsoulis, E., and Assimacopoulos, D. 1994. "Natural Convection Flow in a Square Cavity Revisited: Laminar and Turbulent Models with Wall Functions." International Journal for Numerical Methods in Fluids, 18(7), 695-719.

https://doi.org/10.1002/fld.1650180705

Boulahia, Z., and Sehaqui, R. 2015. "Numerical Simulation of Natura Convection of Nanofluid in a Square Cavity Including a Square Heater." International Journal of Science and Research (IJSR), 4(12), 1718-1722. https://www.ijsr.net/archive/v4i12/NOV152370.pdf

Boulahia, Z., Wakif, A., Chamkha, A. J., and Sehaqui, R. 2017. "Numerical Study of Natural and Mixed Convection in a Square Cavity Filled by a $\mathrm{Cu}$-water Nanofluid with Circular Heating and Cooling Cylinders." Mechanics and Industry, 18(5). https://doi.org/10.1051/meca/2017021 
Transfer of Cu-water Nanofluid in a Lid Driven Square Cavity with Several Heated Triangular Cylinders." International Journal of Innovation and Applied Studies, 17(1), 82.

Boulahia, Z., Wakif, A., and Sehaqui, R. 2016b. "Natural Convection Heat Transfer of the Nanofluids in a Square Enclosure with an Inside Cold Obstacle." International Journal of Innovation and Scientific Research, 21(2), 367-375.

http://www.ijisr.issr-journals.org/abstract.php?article=IJISR-16-032-01

Boulahia, Z., Wakif, A., and Sehaqui, R. 2016c. "Numerical Investigation of Mixed Convection Heat Transfer of Nanofluid in a Lid Driven Square Cavity with Three Triangular Heating Blocks." International Journal of Computer Applications, 143(6), 37-45 https://doi.org/10.5120/ijca2016910227

Boulahia, Z., Wakif, A., and Sehaqui, R. 2016d. "Numerical Study of Mixed Convection of the Nanofluids in Two-Sided Lid-Driven Square Cavity with a Pair of Triangular Heating Cylinders." Journal of Engineering, 2016.

https://doi.org/10.1155/2016/8962091

Boulahia, Z., Wakif, A., and Sehaqui, R. 2017a. "Finite Volume Analysis of Free Convection Heat Transfer in a Square Enclosure Filled by a $\mathrm{Cu}$ Water Nanofluid Containing Different Shapes of Heating Cylinder," Journal of Nanofluid, 6(4), 1-8.

https://doi.org/10.1166/jon.2017.1363

Boulahia, Z., Wakif, A., and Sehaqui, R. 2017b. "MODELING OF FREE CONVECTION HEAT TRANSFER UTILIZING NANOFLUID INSIDE A WAVY ENCLOSURE WITH A PAIR OF HOT AND COLD CYLINDERS." Frontiers in Heat and Mass Transfer, 8.

https://doi.org/10.5098/hmt.8.14

Boulahia, Z., Wakif, A., and Sehaqui, R. 2017c. "Numerical Modeling of Natural Convection Heat Transfer in a Wavy Wall Enclosure Filled by a Cu-water Nanofluid with a Square Cooler,'Journal of nanofluis, 6(2), $1-10$.

https://doi.org/10.1166/jon.2017.1315

Corcione, M. 2010. "Heat Transfer Features of Buoyancy-driven Nanofluids Inside Rectangular Enclosures Differentially Heated at the Sidewalls." International Journal of Thermal Sciences, 49(9), 15361546. https://doi.org/10.1016/j.ijthermalsci.2010.05.005

Corcione, M. 2011. "Empirical Correlating Equations for Predicting the Effective Thermal Conductivity and Dynamic Viscosity of Nanofluids." Energy Conversion and Management, 52(1), 789-793.

https://doi.org/10.1016/j.enconman.2010.06.072

De Vahl Davis, G. 1983. "Natural Convection of Air in a Square Cavity: a Benchmark Numerical Solution.” International Journal for Numerical Methods in Fluids, 3(3), 249-264.

Dixit, H. N., and Babu, V. 2006. "Simulation of high Rayleigh Number Natural Convection in a Square Cavity using the Lattice Boltzmann Method." International Journal of Heat and Mass Transfer, 49(3), 727739. https://doi.org/10.1016/j.ijheatmasstransfer.2005.07.046

El Abdallaoui, M., Hasnaoui, M., and Amahmid, A. 2014. "LatticeBoltzmann Modeling of Natural Convection Between a Square Outer Cylinder and an Inner Isosceles Triangular Heating Body." Numerical Heat Transfer, Part A: Applications, 66(9), 1076-1096.

https://doi.org/10.1080/10407782.2014.894398

El Abdallaoui, M., Hasnaoui, M., and Amahmid, A. 2015. "Numerical Simulation of Natural Convection Between a Becentered Triangular heating Cylinder and a Square Outer Cylinder Filled with a Pure Fluid or a Nanofluid using the Lattice Boltzmann Method." Powder Technology, 277, 193-205. https://doi.org/10.1016/j.powtec.2015.02.042

Guiet, J., Reggio, M., and Vasseur, P. 2012. "Natural Convection of Nanofluids in a Square Enclosure with a Protruding Heater." Advances in Mechanical Engineering, 4, 167296.

https://doi.org/10.1155/2012/167296

Haddad, Z., Oztop, H. F., Abu-Nada, E., and Mataoui, A. 2012. "A Review on Natural Convective Heat Transfer of Nanofluids." Renewable and Sustainable Energy Reviews, 16(7), 5363-5378.

https://doi.org/10.1016/i.rser.2012.04.003

Incropera, F. P., and De Witt, D. P. 2002. Introduction to Heat Transfer (4th ed.). New York: Wiley, c2002.

Islam, A. W., Sharif, M. A. R., and Carlson, E. S. 2012. "Mixed Convection in a Lid Driven Square Cavity with an Isothermally Heated Square Blockage Inside." International Journal of Heat and Mass Transfer, 55(19), 5244-5255.

https://doi.org/10.1016/j.ijheatmasstransfer.2012.05.032

Iwatsu, R., Hyun, J. M., and Kuwahara, K. 1993. "Mixed Convection in a Driven Cavity with a Stable Vertical Temperature Gradient." International Journal of Heat and Mass Transfer, 36(6), 1601-1608. hhttps://doi.org/10.1016/S0017-9310(05)80069-9

Kalidasan, K., and Kanna, P. R. 2017. "Natural Convection on an Open Square Cavity Containing Diagonally Placed Heaters and Adiabatic Square Block and Filled with Hybrid Nanofluid of Nanodiamond - cobalt oxide / water." International Communications in Heat and Mass Transfer, 81, 64-71.

https://doi.org/10.1016/j.icheatmasstransfer.2016.12.005

Kalteh, M., Javaherdeh, K., and Azarbarzin, T. 2014. "Numerical Solution of Nanofluid Mixed Convection Heat Transfer in a Lid-Driven Square Cavity with a Triangular Heat Source." Powder Technology, 253, 780-788.

https://doi.org/10.1016/j.powtec.2013.12.039

Khanafer, K., and Aithal, S. M. 2013. "Laminar Mixed Convection Flow and Heat Transfer Characteristics in a Lid Driven Cavity with a Circular Cylinder." International Journal of Heat and Mass Transfer, 66, 200 209. https://doi.org/10.1016/j.ijheatmasstransfer.2013.07.023

Kolsi, L., Kalidasan, K., Alghamdi, A., Borjini, M. N., and Kanna, P. R. 2016. "Natural Convection and Entropy Generation in a Cubical Cavity with Twin Adiabatic Blocks Filled by Aluminum Oxide-water Canofluid." Numerical Heat Transfer, Part A: Applications, 70(3), 242259. https://doi.org/10.1080/10407782.2016.1173478

Mamun, M. A. H., Rahman, M. M., Billah, M. M., and Saidur, R. 2010. "A Aumerical Study on the Effect of a Heated Hollow Cylinder on Mixed Convection in a Ventilated Cavity." International Communications in Heat and Mass Transfer, 37(9), 1326-1334.

https://doi.org/10.1016/j.icheatmasstransfer.2010.07.019

Mehrizi, A. A., Farhadi, M., Afroozi, H. H., Sedighi, K., and Darz, A. A. R. 2012. "Mixed Convection Heat Transfer in a Ventilated Cavity with Hot Obstacle: Effect of Nanofluid and Outlet Port Location is." International Communications in Heat and Mass Transfer, 39(7), 10001008. https://doi.org/10.1016/j.icheatmasstransfer.2012.04.002

Najam, M., El Alami, M., and Oubarra, A. 2004. "Heat Transfer in a 'T' form Cavity with Heated Rectangular Blocks Submitted to a Vertical Jet: 9 the Block Gap Effect on Multiple Solutions." Energy Conversion and 
Management, 45(1), 113-125.

https://doi.org/10.1016/S0196-8904(03)00126-2

Oztop, H. F., Zhao, Z., and Yu, B. 2009. "Fluid Flow due to Combined Convection in Lid-driven Enclosure having a Circular Body." International Journal of Heat and Fluid Flow, 30(5), 886-901. https://doi.org/https://doi.org/10.1016/j.ijheatfluidflow.2009.04.009

Park, H. K., Ha, M. Y., Yoon, H. S., Park, Y. G., and Son, C. 2013. “A Numerical Study on Natural Convection in an Inclined Square Enclosure with a Circular Cylinder." International Journal of Heat and Mass Transfer, 66, 295-314.

https://doi.org/10.1016/j.ijheatmasstransfer.2013.07.029

Patankar, S. 1980. Numerical heat transfer and fluid flow. McGraw-Hill, Washington: CRC press.

Rahman, M. M., Parvin, S., Rahim, N. A., Islam, M. R., Saidur, R., and Hasanuzzaman, M. 2012. "Effects of Reynolds and Prandtl Number on Mixed Convection in a Ventilated Cavity with a Heat-Generating Solid Circular Block." Applied Mathematical Modelling, 36(5), 2056-2066. https://doi.org/10.1016/j.apm.2011.08.014

Shahi, M., Mahmoudi, A. H., and Talebi, F. 2010. "Numerical Study of Mixed Convective Cooling in a Square Cavity Ventilated and Partially Heated from the Below Utilizing Nanofluid." International Communications in Heat and Mass Transfer, 37(2), 201-213. https://doi.org/10.1016/j.icheatmasstransfer.2009.10.002

Spalding, D. B. 1972. "A Novel Finite Difference Formulation for Differential Expressions Involving Both First and Second Derivatives." International Journal for Numerical Methods in Engineering, 4(4), 551559.

https://doi.org/10.1002/nme.1620040409

Varol, Y., Oztop, H. F., and Yilmaz, T. 2007. "Natural Convection in Triangular Enclosures with Protruding Isothermal Heater." International Journal of Heat and Mass Transfer, 50(13), 2451-2462. https://doi.org/10.1016/j.ijheatmasstransfer.2006.12.027
Wakif, A., Boulahia, Z., and Sehaqui, R. 2017a. "Numerical Analysis of the Onset of Longitudinal Convective Rolls in a Porous Medium Saturated by an Electrically Conducting Nanofluid in the Presence of an External Magnetic Field." Results in Physics, 77, 2134-2152.

https://doi.org/10.1016/j.rinp.2017.06.003

Wakif, A., Boulahia, Z., and Sehaqui, R. 2017b. "Numerical Study of the Onset of Convection in a Newtonian Nanofluid Layer with Spatially Uniform and Non Uniform Internal Heating." Journal of Nanofluids, 6(1), 136-148.

https://doi.org/10.1166/jon.2017.1293

Wakif, A., Boulahia, Z., Ali, F., Eid, M. R., and Sehaqui, R. 2018 a. "Numerical Analysis of the Unsteady Natural Convection MHD Couette Nanofluid Flow in the Presence of Thermal Radiation Using Single and Two-Phase Nanofluid Models for $\mathrm{Cu}-$ Water Nanofluids." International Journal of Applied and Computational Mathematics, 4(3), 81. https://doi.org/10.1007/s40819-018-0513-y

Wakif, A., Boulahia, Z., and Sehaqui, R. 2018b. "A Semi-analytical Analysis of Electro-thermo-hydrodynamic Stability in Dielectric Nanofluids using Buongiorno's Mathematical Model Together with More Realistic Boundary Conditions.” Results in Physics, 9, 1438-1454. https://doi.org/10.1016/j.rinp.2018.01.066

Wakif, A., Boulahia, Z., Mishra, S.R., Rashidi, M.M., and Sehaqui, R. 2018c. "Influence of a Uniform Transverse Magnetic Field on the Thermo-Hydrodynamic Stability in Water-Based Nanofluids with Metallic Nanoparticles Using a Generalized Buongiorno's Mathematical Model.” Eur. Phys. J. Plus, 133(5), 181.

https://doi.org/10.1140/epjp/i2018-12037-7

Xu, H., Xiao, R., Karimi, F., Yang, M., and Zhang, Y. 2014. "International Journal of Thermal Sciences Numerical study of double diffusive mixed convection around a heated cylinder in an enclosure.", 78, 169-181.

https://doi.org/10.1016/j.ijthermalsci.2013.12.016. 